\title{
Plant response to jasmonates: current developments and their role in changing environment
}

\author{
Khwaja Salahuddin Siddiqi ${ }^{1}$ and Azamal Husen ${ }^{2^{*}}$ (D)
}

\begin{abstract}
Jasmonates (JAs) are universally known lipid-derived phytohormones which regulate overall plant growth under both abiotic and biotic stresses. They are helpful in developing root and reproductive system in plants. Also, JA signaling triggers gene expression. They coordinate with other plant hormones under changing environmental conditions. JAs alone or sometimes in combination with other plant hormones ameliorate stress conditions. They also participate in upregulation of antioxidant metabolism, osmolyte synthesis, and metabolite accumulation. Pretreatment and/or exogenous application of JA exhibited multi-stress resilience under changing environment as well as other biotic stress conditions. The present review focuses on our current understanding of how plants respond to JAs' application under extremely low or high temperature, highly alkaline condition, or even when attacked by herbivorous insects/animals. As a consequence of injury, the plant produces defense molecules to protect itself from damage. Their major role and mechanism of action under heavy metal/metalloid-induced toxicity have also been discussed.
\end{abstract}

Keywords: Jasmonates, Hormones, Signaling, Plant growth and development

\section{Background}

Plants are exposed to a variety of abiotic and biotic stresses such as drought, salinity, acidity, flooding, cold, heat, metal, and metalloid-induced toxicity. These stresses adversely influence the growth and yield of plants (Husen et al. 2014; Getnet et al. 2015; Embiale et al. 2016; Bernal-Vicente et al. 2018; Yurchenko et al. 2018; Balfagón et al. 2018). Even though plant hormones are produced in very low amounts, they regulate many external and internal stimuli (Kazan 2015; Siddiqi and Husen 2017; Pandey et al. 2017; Husen et al. 2018, 2019; Pandey et al. 2017; Podlešáková et al. 2019). They play a vital role in saving the plant from stress and improve quality of crops (Kazan 2013; Santino et al. 2013; Colebrook et al. 2014; Husen et al. 2016, 2017, 2018; Hanaka et al. 2018).

Jasmonic acid (JA) and its cyclopentanone derivatives are produced by plants. They are collectively known as

\footnotetext{
* Correspondence: adroot92@yahoo.co.in

${ }^{2}$ Wolaita Sodo University, P.O. Box \# 138, Wolaita, Ethiopia

Full list of author information is available at the end of the article
}

jasmonates (JAs). These multifunctional hormones are involved in plant development and defense processes (Seo et al. 2001; Huang et al. 2017; Per et al. 2018). Besides developmental functions of plants, JAs activate plants against pathogens and environmental stresses (Pauwels et al. 2009; Seo et al. 2011). It has also been reported that JAs are signaling hormones induced under stress and respond quickly to them ( $\mathrm{Du}$ et al. 2013). They are involved in plant development, reproduction (Wasternack 2007; Browse 2009) floral development, growth inhibition, fruit ripening, tendril coiling, potato tuberization, trichome formation, and fungi arbuscular micorrhizal association (Browse 2005; Balbi and Devoto 2008; Reinbothe et al. 2009; Yoshida et al. 2009). JA also acts as a regulator of leaf and root morphogenesis in soybean (Xue and Zhang 2007) and control plant fertility. It has been found that Arabidopsis mutants deficient in JA synthesis are male sterile (Ishiguro et al. 2001; Park et al. 2002; von Malek et al. 2002). JA also controls overall development related to expression of numerous genes in stamen tissue (Song et al. 2011). 
Per et al. (2018) have reported specific role of JA under abiotic stress. However, Kazan (2015) has reviewed the diverse roles of JA and ethylene in abiotic stress tolerance. JA and ethylene regulate root development and anthocyanin accumulation which may be associated with abiotic stress tolerance. Biotic stress in plants is caused by viruses, bacteria, fungi, nematodes, parasites, and insects/pests. In order to protect themselves, plants develop a mechanism in defense. Such responses are mediated by JA, salicylic acid (SA), brassinosteroids, ethylene, polyamines, and abscisic acid (ABA) acting as primary signals in regulation of plant defense. For instance, defense response against biotrophic pathogens is mediated by SA (Durrant and Dong 2004) while JA and ethylene mediate responses against necrotrophs (Glazebrook 2005). However, attack by pathogens and mode of defense by plants may vary from species to species. JAs have also been examined for secondary metabolite production. Ren and Dai (2012) have reported that JA involved in the signaling pathway for fungal (AL12 - Gilmaniella sp.) endophyte-induced volatile oil from Atractylodes lancea plantlets exhibits antimicrobial activity. Secondary metabolites (terpenes, flavonoides, and alkaloids) present in the oil are supposed to be involved in plant responses to biotic and abiotic stresses (Rodriguez et al. 2009; Mucciarelli et al. 2007; Wang et al. 2010). Plants produce JA in defense during infection or any treatment. Other signaling molecules have also been found to be associated with secondary metabolism (Yuan et al. 2001; Nojiri et al. 1996; Gao et al. 2012). For instance, SA activates defense-related genes, which, in turn encode pathogenesis related proteins (Van and Van 1999). Kunkel and Brooks (2002) have shown that fungal elicitor caused increase in JA production, secondary metabolites biosynthetic gene expression, and metabolite accumulation in many plants. Ren and Dai (2012) have found that when endophytic fungus was inoculated in A. lancea, it triggered JA biosynthesis which increased quantity of oil in the plant. Besides, JA, $\mathrm{NO}, \mathrm{H}_{2} \mathrm{O}_{2}$, and SA are also known to mediate the signaling pathway in $A$. lancea plantlets (Wang et al. 2011a). However, JA may act as downstream signal of $\mathrm{NO}$ while $\mathrm{H}_{2} \mathrm{O}_{2}$ acts as intermediate factor between JA and NO. It has been observed that $\mathrm{H}_{2} \mathrm{O}_{2}$, SA, and JA may work together in fungus-induced volatile oil synthesis in A. lancea plantlets. However, it has been reported previously (Wang et al. 2011b) that NO mediates volatile oil accumulation induced by fungus via SA- and $\mathrm{H}_{2} \mathrm{O}_{2}$ dependent pathways. JA and SA are equally important signaling molecules in plant defense responses. When the biosynthesis of one component such as JA is suppressed by some inhibitor, accumulation of SA is enhanced and vice versa. Thus, JA works as a downstream signaling molecule in $\mathrm{NO}$ and $\mathrm{H}_{2} \mathrm{O}_{2}$ mediates volatile oil accumulation induced by entophytic fungus. JA synthesis occurs through oxylipin biosynthesis pathway (Wasternack 2007; Gfeller et al. 2010) during herbivore attack. The effects of methyl jasmonate (MJ), JA, and cis-jasmone on anthocyanins and procyanidins have been studied (Horbowicz et al. 2009). JAs either as in the form of solution or vapor has been applied (Horbowicz et al. 2009). JA stimulated the anthocyanin accumulation when applied as solution but when used as vapor, it decreased the accumulation in Fagopyrum esculentum hypocotyls. JA solution had negligible effect on biosynthesis of anthocyanins in buckwheat seedlings. MJ works by moving in both phloem and xylem perhaps due to a difference in biochemical behavior (Zhang and Boldwin 1997). In another experiment, 21-day-old melon (Cucumis melo) cells treated with JA at very low concentration (0.5, 5.0, and $10 \mu \mathrm{mol}$ ) were checked for defense-related factors like antioxidant enzymes, ascorbate metabolism, and phenolic compounds. It was found that JA induced primary and secondary metabolism in melon cells (Nafie et al. 2011) by producing bioactive molecules in defense. Melon cells exhibited enhanced oxidative enzyme activities and ascorbic acid, coumarin, and p-coumaric amounts without growth retardation. Induced intracellular JA functions as signal transducer acting upstream to $\mathrm{H}_{2} \mathrm{O}_{2}$ and regulate the antioxidant activity of catalase (CAT), peroxidase (POD), and synthesis of five isozymes and ascorbic POD detoxifying enzymes. It is certain that the production of secondary metabolites in melon cells is activated by JA and induces melon resistance. CAT activity was increased by $24 \%$ at $10 \mu \mathrm{mol}$ JA. JA application stimulates many responses in plants including synthesis of hormones, gene expression, crop production, and defense against biotic/abiotic stress (Ahmad et al. 2016). JA increased the POD activity up to $137 \%$ after $24 \mathrm{~h}$. The enzyme activity revealed the presence of five POD isoforms. Ascorbate peroxidase (APX), ascorbic oxidase, and glutathione reductase (GR) also increased. APX helps in detoxification of $\mathrm{H}_{2} \mathrm{O}_{2}$ according to the reaction given below:

2 ascorbate $+\mathrm{H}_{2} \mathrm{O}_{2} \rightarrow 2$ monodehydroascorbate $+2 \mathrm{H}_{2} \mathrm{O}$

Hamberg and Gardner (1992) have reported that hydroxylated JA derivatives are more useful and regulate tuber formation in potato, but the process is also controlled by light, temperature, and gibberellic acid (Lin et al. 2013). It means that JAs control tuber formation indirectly through crosstalk with GA signaling (Wasternack and Hause 2013). Reactive oxygen species (ROS) is generated under stress, causing damage to plants by oxidation of lipids, proteins, and nucleic acid (Gille and Singler 1995; Gill and Tuteja 2010). JA and MJ also increase antioxidant activity in raspberry fruit (Ghasemnezhad and Javaherdashti 2008). JAs also increase resistance of plants against pests in field pots of tomato (Thaler et al. 2001). They also provide resistance to edible plants and vegetables against fungi and nematodes 
(Schmelz et al. 2002; Soriano et al. 2004). MJ and cis-jasmone (James 2005) have also been shown to repel herbivores in plants. Effect of different concentrations of JA on the growth of flower, height, and weight of marigold plant has been reported. JA increases the dry weight of flower, plant height, and 1000 seed weight (Ataei et al. 2013). Height and weight increased with increasing concentration of JA and attained maximum at a concentration of $150 \mu \mathrm{M}$ JA. The number of flowers also increased but carotenoids decreased with increasing concentration of JA above $75 \mu \mathrm{M}$. JA regulates photosynthesis but MJ and JA together increase plant resistance to infection by green mold (Rohwer and Erwin 2008). Sasaki-Sekimoto et al. (2005) have demonstrated that ozone exposure caused induction of numerous genes involved in antioxidant metabolism in the wild type. But, in JA-deficient Arabidopsis 12-oxophytodienoate reductase 3 (opr3) mutants, the induction of antioxidant genes was stopped. Arabidopsis opr3 mutants were found to be more sensitive due to ozone exposure in comparison to wild type. It has been suggested that the coordinated activation of the metabolic pathways mediated by JAs provides resistance to under stress conditions.

Although, cancer preventive effect of some vegetables such as broccoli, cauliflower, or cabbage is known (van Poppel et al. 1999), the chemical responsible for it has recently been explored (Farooqi et al. 2012). JAs have been found to be active against several human cancer cell lines (Cohen and Flescher 2009). The activity is due to interference of JAs with energy metabolism mitochondrial perturbation and production of ROS leading to cell death. JA, MJ, and cis-jasmone are highly effective in cancer therapy. Extract from Viscum album, Jasminum, Chloranthus, Cymbidium, Rosmarinus, and Lonicera plants contain fairly large quantity of JA and MJ. Activity mediated by JA/MJ is given by its induction of biosynthesis of glucosinolates in cruciferous vegetables. Treatment of cauliflower by $\mathrm{MJ}$ before harvesting increased glucosinolate up to 5-fold and increased marker enzymes of anticancer bioactivity (Ku et al. 2013).

In this review, we have discussed the current status of the application of JAs in plants and their response under changing environmental conditions. Moreover, a summary of major role of JAs on various plant growth and developmental processes is presented in Fig. 1.

\section{Biosynthesis of JA}

Most fascinating and interesting role of JA includes plant stress responses, signaling, and metabolic pathways. Several processes such as seed germination, root growth, flower development, and tuber formation have been shown to be regulated by JA/JA-Ile ( $N$-jasmonoylL-isoleucine). JA/JA-Ile are involved in metabolic function, signaling, and interaction with other hormones (Katsir et al. 2008; Kombrink 2012; Pieterse et al. 2012). Fatty acid substrate of JA biosynthesis is $\alpha$-linolenic acid (Ahmad and Jhon 2005; Cervilla et al. 2007) which is released from galactolipids of chloroplast membranes.

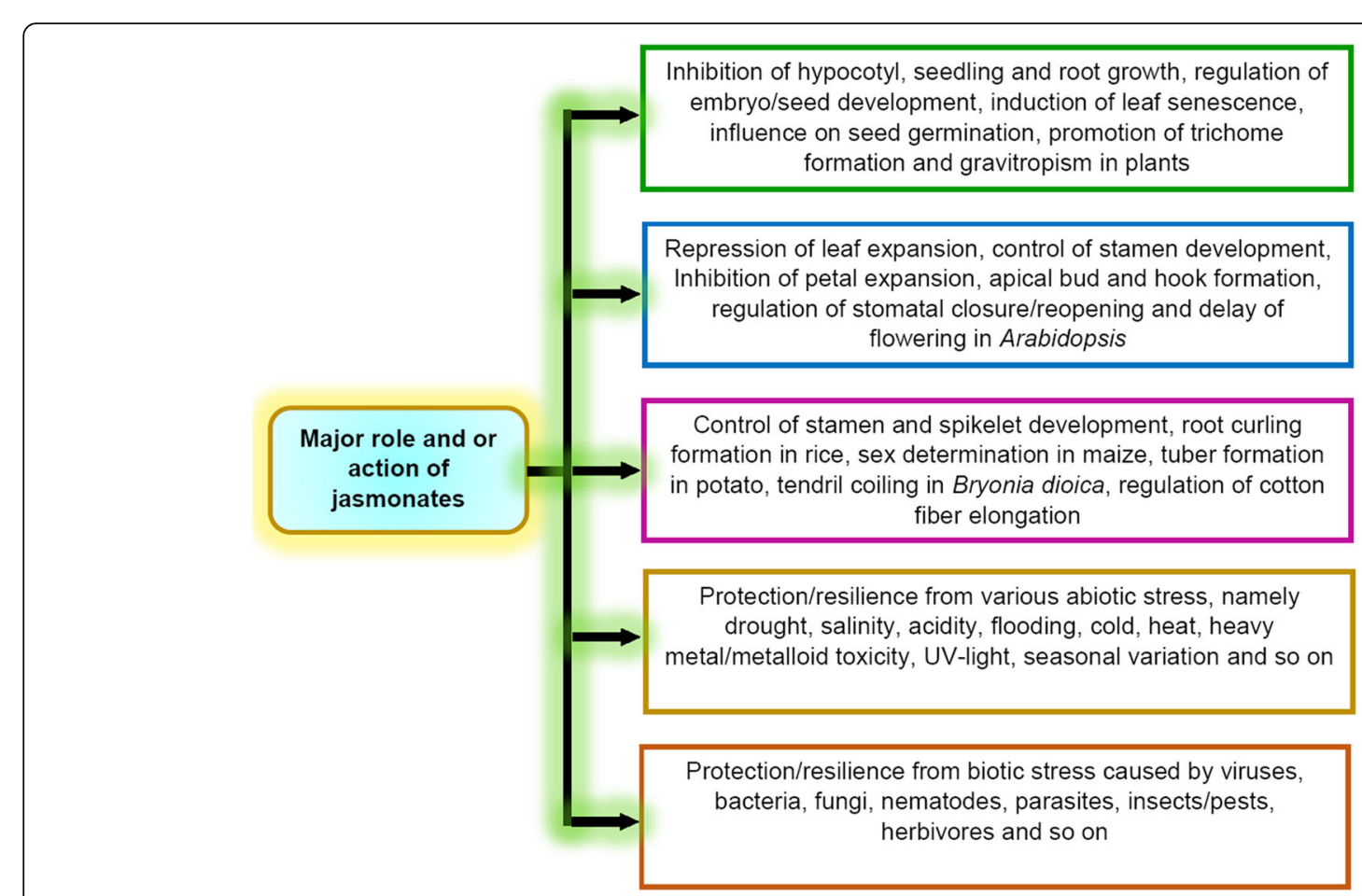

Fig. 1 The role of JAs on plant growth and developmental processes 
Phospholipase 1 is responsible for generation of the JA substrate. Wound- and pathogen-induced biosynthesis of JA is faster (Yang et al. 2007) where unidentified lipases may be involved (Ellinger et al. 2010). Acids and enzymes are released upon stress as a defense signal (Jung et al. 2009; Zoeller et al. 2012). $\mathrm{Ca}^{2+}$-dependent protein kinases are negative regulators in wound and herbivore-induced JA accumulation (Yang et al. 2012). A wound-induced protein kinase (WIPK) is quickly activated around the wound inducing JA biosynthesis (Wu et al. 2007). Per et al. (2018) have recently reviewed the biosynthesis of JA. The mechanism underlying the synthesis and signaling pathway has been discussed (Fig. 2). First step in the biosynthesis of JA involves oxidation of phospholipid $\alpha$-linolenic acid, in the presence of phospholipases to 12-oxophytodienoic acid (Bannenberg et al. 2009). After a chain of oxidation reactions in the presence of various enzymes, JA and its derivatives are produced (Kombrink 2012; Wasternack and Hause 2013).

\section{Role of JA under changing environment}

Plants under adverse environmental conditions regulate their developmental and physiological processes. Such conditions are often correlated with global warming (climate abnormalities) which directly or indirectly lead to the concurrence of a number of stresses. They also influence plant growth and productivity. JA is a proven endogenous regulator of stress responses and overall plant growth and productivity.

\section{Role of JA under salinity stress}

Salt stress in plants is caused mainly owing to high $\mathrm{Na}^{+}$and $\mathrm{Cl}^{-}$ion concentrations in the soil. $\mathrm{Na}^{+}$retained in the woody roots and $\mathrm{Cl}^{-}$accumulated in shoots caused severe damage to plants (Moya et al. 2003). Salt stress decreases the dry weight of root/shoots and root length, but there is a simultaneous decrease in $\mathrm{K}^{+}, \mathrm{Ca}^{2+}$, and $\mathrm{Mg}^{2+}$ concentration in shoots of plant (Munns and Termaat 1986; Yeo and Flowers 1986). Kang et al. (2005) have investigated the effect of salt stress and recovery by applying JAs to two different rice (Oryza sativa) cultivars, Dongiinchalbyeo (DJC, salt tolerant), and Dongjinbyeo (DJ, salt sensitive). Salt stress significantly decreased the root length of plants even at very low $\mathrm{NaCl}$ concentration $(20 \mathrm{mM})$ with a simultaneous increase in the ABA concentration. ABA concentration in the salt tolerant variety of rice increased with increasing $\mathrm{NaCl}$ concentration while in salt sensitive cultivar, ABA sharply decreased in all parts of rice plants. JA was found to decrease in both the salt sensitive (DJ) and salt tolerant (DJC) rice cultivars. Post application in stressed plants with $30-\mu \mathrm{M} \mathrm{JA}$ and 24 and $4 \mathrm{~h}$ after $\mathrm{NaCl}$ treatment, removed salt inhibition on dry mass production more effectively than prior application of JA, before salt stress. Uptake of $\mathrm{Na}$ decreased with a consequent increase in $\mathrm{Ca}$, $\mathrm{Mg}$ levels, and a little increase in K by JA application. Salt-

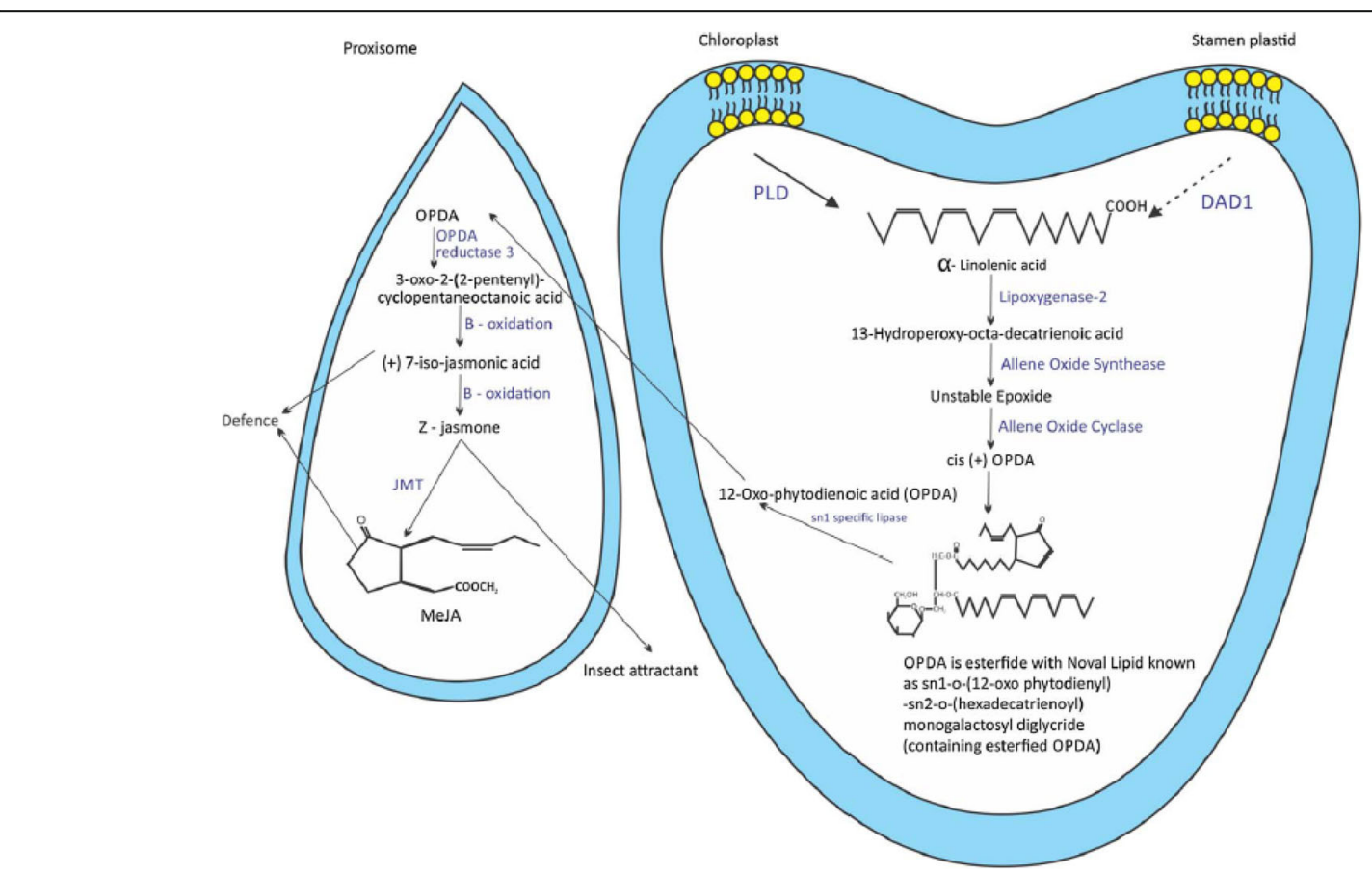

Fig. 2 Major steps involved in the synthesis of methyl jasmonates (MeJA) from a-linolenic acid (adopted from Per et al. 2018; re-drawn based on Wasternack and Song 2017) 
sensitive cultivar accumulated more $\mathrm{Na}^{+}$than salt tolerant cultivar plants in the roots and shoots after $\mathrm{NaCl}$ treatment. Taken together, JA improved recovery of salt-stressed rice seedlings. Walia et al. (2006) have reported that the induction of JA-responsive genes in barley was considered as a crucial aspect under salinity. They (Walia et al. 2007) have further reported that three JA-regulated genes activate arginine decarboxylase and apoplastic invertase which were probably involved in salinity tolerance mediated by JA. It has been reported that leaves accumulate ABA at high level under salt stress (Hurkman and Tanaka 1996; Moons et al. 1997). ABA accumulation is very sensitive to dehydration of leaf tissue. It also helps in triggering gene expression upon wounding and pathogenic infection (Moons et al. 1997). ABA causes stomatal closure (during dehydration/ water stress) preventing loss of water through transpiration under water stress imposed by high $\mathrm{NaCl}$ concentration (Zeevaart and Creelman 1988). When JA is applied under stressed condition of plants, the conditions are reversed.

Yoon et al. (2009) have studied the influence of $\mathrm{NaCl}$ stress on soybean and reduction in stress by MeJA application under hydroponic condition. A very low concentration was applied to soybean seedlings under $\mathrm{NaCl}$ stress. It induced appreciable reduction in plant growth, endogenous bioactive gibberellin (GA), photosynthesis, and transpiration rate with a consequent increase in endogenous $\mathrm{ABA}$ and proline contents. Salt stress has been shown to reduce the biomass of tomato (Kaya et al. 2001), pea (Ahmad and Jhon 2005), and rice (Yeo et al. 1999) even though shoot dry weight is more sensitive to salinity than root dry weight (Essa 2002). However, the effect of salt stress was insignificant on root dry weight of soybean. MJ application induced ABA production in soybean stressed plant as a defense mechanism.

Most edible plants and vegetables exhibit limited growth and development in highly saline soil. High salinity has been reported to cause reduction in growth, lipid peroxidation, and $\mathrm{H}_{2} \mathrm{O}_{2}$ accumulation (Charparzadeh et al. 2004). It has also been reported that with increasing concentration of $\mathrm{NaCl}$ soluble proteins, sugars and total free amino acids including proline were progressively accumulated in alfalfa (Antoline and Sauchez-Dais 1992). JAs may act as modulator by suppressing the stress responses of plants (Popova et al. 1995). Sheteawi (2007) has investigated the possible ameliorative effect of JA and ascobin (ascorbic acid + citric acid, 2:1) on $\mathrm{NaCl}$ stressed soybean. He noted that JA mitigated the inhibitory effect of $\mathrm{NaCl}$ on the growth parameters of soybean. Foliar spray or seed soaked in JA showed better growth. Fresh growth (174\%) and dry weight of the plant (129\%) were increased when soybean plant stressed with $\mathrm{NaCl}$ was sprayed with ascobin (Khan et al. 2003). However, plants salinized with $100 \mathrm{mM} \mathrm{NaCl}$ showed stunted growth even when sprayed with ascobin or JA perhaps due to high salinity beyond tolerance limit of plant
(Cherki et al. 2002). Ascobin or JA in salt-stressed plants act as antioxidant and protect them from damaging by salinity. They also increased the N, P, and K level in soybean and enhanced accumulation of non-toxic metabolites such as proteins, sugars, and proline.

In an experiment foliar application of JA was done on wheat seedlings for 3 days and subsequently subjected to $\mathrm{NaCl}$ solution (Qiun et al. 2014). Salinity thus produced decreased plant height, root length, shoot and dry weight, chlorophyll b, and carotenoid. The superoxide dismutase (SOD), POD, CAT, and APX activities were decreased under salt stress in wheat seedlings. Exogenous JA coupled with $\mathrm{NaCl}$ treated wheat seedlings showed significantly increased level of SOD, POD, CAT, and APX activities. Expression level of SOD, POD, CAT, and APX genes was significantly upregulated in wheat seedlings under salinity stress even when seedlings were not pre-treated with JA. It has been noted that exogenous JA treatment neutralize $\mathrm{NaCl}$-induced oxidative stress which is reflected by a decrease in MDA and $\mathrm{H}_{2} \mathrm{O}_{2}$ concentration and the production rate of peroxide radical. Thus, JA helps in scavenging free radicals preventing lipid peroxidation by excess ROS produced during salinity stress. SOD acts as an antioxidant in plant cells, and its activity is increased in wheat seedlings treated with exogenous JA (Qiun et al. 2014). Exogenous JA also enhances APX, CAT, and POD activities in wheat seedlings (Qiun et al. 2014) similar to that observed by Noriega et al. (2011) in the case of soybean under cadmium stress. Enhancement in activity of above enzymes in soybean and wheat is a consequence of defensive mechanism under salt and drought stress (Anjum et al. 2011). Thus, exogenous JA application in wheat seedlings can enhance their tolerance to salt stress which is indicated by decreasing concentration of MDA and $\mathrm{H}_{2} \mathrm{O}_{2}$, etc. During salinity stress, forced uptake of $\mathrm{Na}^{+}$ions into cytoplasm acts as a signal, triggering salinity adaptation (Ismail et al. 2014). Sodium ion concentration also increases during drought condition similar to that produced during salinity.

\section{High $\left[\mathrm{Na}^{+}\right] \rightarrow$ cytoplasm signal triggering salinity adaptation}

Alkalinity and salinity stresses are synonymously used though in terms of $\mathrm{pH}$ they are different except that sodium ion concentration is identical for a given concentration of $\mathrm{NaCl}$ and $\mathrm{NaOH}$ (Wang et al. 2011a, 2011b). The alkaline sodium stress is therefore worse than saline stress because the soil becomes highly basic as shown below:

$$
\begin{aligned}
& \mathrm{NaCl} \rightarrow \mathrm{Na}^{+}+\mathrm{Cl}^{-} \text {neutral, pH7 } \\
& \mathrm{NaOH} \rightarrow \mathrm{Na}^{+}+\mathrm{OH}^{-} \text {alkaline, } \mathrm{pH}>7
\end{aligned}
$$

The $\mathrm{OH}^{-}$ions actually precipitate the essential nutrients and trace elements in the soil preventing their absorption by plants ( $\mathrm{Li}$ et al. 2009). However, organic acids may 
neutralize a small fraction of $\mathrm{OH}^{-}$ions in the soil according to the following equation.

$$
\mathrm{NaOH}+\mathrm{CH}_{3} \mathrm{COOH} \rightarrow \mathrm{CH}_{3} \mathrm{COONa}+\mathrm{H}_{2} \mathrm{O}
$$

JA at this stage sends adaptation signals such as stomatal closure to prevent loss of water by transpiration. ABA helps in closing and opening of stomata during drought and high salinity since it is accumulated in plants under stress. Closing/opening of stomata depends on the ionic concentration of $\mathrm{Na}$ and $\mathrm{Ca}$ ions and the osmotic pressure. JA contents also increase in maize root cells under drought conditions (Xin et al. 1997). Exogenous application of JA and MJ increases antioxidative activity of plants under water stress (Bandurska et al. 2003) because it enhances the activity of antioxidative enzymes (Nafie et al. 2011). However, JA under normal conditions can enhance the growth and yield but this process under saline and drought condition is delayed. Kim et al. (2009a) have studied the influence of JA on endogenous gibberellin acid and ABA in salt-stressed chard plant. They have shown the effect of JA application before and after the stress produced by $\mathrm{NaCl}$. Endogenous ABA content was increased by JA treatment (75\%). Similar result has also been reported by Wang et al. (2001). Exogenous application of MJ significantly mitigates salinity stress symptoms in soybean seedling (Yoon et al. 2009). Ahmad et al. (2018) have reported that the exogenous application of JA and NO alleviated $\mathrm{NaCl}$ toxicity in tomato by controlling the antioxidant metabolism, osmolyte synthesis, and metabolite accumulation. Mir et al. (2018) have also suggested that the pretreatment of maize seedlings with JA mitigated the toxic effects of excessive $\mathrm{Na}_{2} \mathrm{CO}_{3}$ on plant growth and photosynthesis. Yuan et al. (2018) have also reported that the exogenous application MJ alleviates the reduced growth of Limonium bicolor under salt stress. They have shown that the exposure of $300-\mathrm{mM} \mathrm{NaCl}$ inhibited seedling growth, while adverse effects of $\mathrm{NaCl}$ was mitigated by the exogenous application of $0.03-\mathrm{mM}$ MeJA, resulting in a biomass close to the control plants. In a very recent study, Liu et al. (2019) have reposted that a moss jasmonate ZIM-domain gene acts as a repressor, mediates JAABA synergistic crosstalk, and enhances plant growth under salt stress. However, for better understanding, the molecular mechanism of the interaction between $\mathrm{ABA}$ signaling and JA signaling is still need more investigation.

\section{Role of JA under drought stress}

Stomatal closure in plants limits the transpiration to retain water under drought conditions. ABA interacts with other plant hormones like JA and NO to stimulate stomatal closure. Stress-induced production of JA interacts with ABA-mediate stomatal closure by stimulating the influx of extracellular $\mathrm{Ca} 2+$ or/and by activating $\mathrm{H}_{2} \mathrm{O}_{2}$ / NO signaling (Harrison 2012). Many JA-associated signaling genes are regulatory drought stress (Huang et al. 2008). Stomatal aperture of Arabidopsis leaves has been found to be drastically reduced when treated with M) for 10 min (Munemasa et al. 2007). It has been hypothesized that both $\mathrm{ABA}$ and $\mathrm{MJ}$ interact in guard cells and induce the formation of ROS and NO. Kim et al. (2009b) have shown that drought stress induces 19-fold increase in MJ level and 1.4-fold increase in ABA levels. These hormones affect the grain yield and their own biosynthesis. The plant hormone ABA, as a stress signal, also increases during water stress. ABA can also induce the expression of antioxidant gene encoding APX and GR in seedlings (Jiang and Zhang 2002; Hu et al. 2007). JA is helpful in regulating plant response under water scarcity (Liu et al. 2005). Water deficiency also cause damage to growing leaves due to induced osmotic effect which, in turn causes proline accumulation. It could be reversed after desalination (Nandwal et al. 2000). It has been practically demonstrated that under water scarcity induced by PEG 6000 in Agropyron cristatum, JA level, the transcript level, and activities of ascorbate peroxidase (APX), GR, monodehydroascorbate reductase, dehydroascorbate reductase (DHAR), L-galactono-1,4-lactone dehydrogenase, and $\gamma$-glutamylcysteine synthetase and ascorbic acid, glutathione, total ascorbate, and total glutathione were increased (Shan and Liang 2010). MJ treated Allium sativum L. under drought stress showed increase in shoot, root, and bulb growth (Bideshki and Arvin (2013). Total chlorophyll, anthocyanins, membrane permeability, root length, and growth were also significant. However, a combination of indole 3-butyric acid (IBA) and $\mathrm{MJ}$ is more effective for growth promotion under normal condition. However, IBA alone is ineffective under stress, although MJ enhances both the growth and yield.

\section{Role of JA under heavy metal/metalloid induce toxicity}

Although many metal ions are essential nutrients some are toxic to both plants and animals (Hou et al. 2007; Asgher et al. 2015; Iqbal et al. 2015). Excess of essential metals or even metalloid induce toxicity in plants, which may result into oxidative stress leading to physiological changes (Dhankar and Solanki 2011). JA application, however, enhanced accumulation of osmolytes while carotenoids enhanced antioxidant enzyme concentration which prevented the plants from damage by excess metal ions (Poonam et al. 2013). Pigeon pea exposed to JA showed accumulation of proteins (and total chlorophyll, carotenoids) and reduced the effect of copper (II) on the growth of seedlings. Excess cadmium produces $\mathrm{ROS}, \mathrm{H}_{2} \mathrm{O}_{2}$, and superoxide radicals which cause oxidative damage in plants (Gallego et al. 2012). However, MJ application 
reduces this damage by about $30 \%$ in soybean and $A$. thaliana (Maksymiec et al. 2005). Excess boron in the soil may be absorbed by plants and can cause visible damage such as leaf burn, decreased fruit size (Paull et al. 1992; Nable et al. 1997) besides ROS production in wheat, (Gunes et al. 2007) barley (Inal et al. 2009), and tomato (Cervilla et al. 2007). Foliar spray of MJ alleviated the above symptoms significantly by stimulating the antioxidant production with a consequent reduction in lipid peroxidation. Heavy metal stress is also alleviated by activating the antioxidant system (Yan et al. 2013). MJ strengthened tolerance in A. thaliana plants against copper and cadmium stress through accumulation of chelating ligands which form complex with metal ions and prevent their availability to plant. Singh and Shah (2014) reported that under cadmium stressed O. sativa, application of MJ exhibited remarkable changes in activity of CAT, SOD, and GR paralleled with increased glutathione pools. MJ application at $0.1 \mu \mathrm{M}$ concentration increased plant dry weight, leaf chlorophyll content, CAT, and APX activity in Cd-treated Capsicum frutescens (Yan et al. 2013). Yan et al. (2015) also reported that MJ at 1.0 and $10 \mu \mathrm{M}$ concentrations decreased uptake of $\mathrm{Cd}$ and increased APX activity in Avicennia marina. In another study, Chen et al. (2014) showed that exogenous application of MJ in Kandelia obovata also maintained endogenous level of JA, controlled stomatal closure, reduced transpiration rate, prevented the uptake of $\mathrm{Cd}$, and reduced photosynthetic damage. Ahmad et al. (2017) have also suggested that JA mitigates the deleterious effects of Cd stress in Vicia faba by preventing the accumulation of $\mathrm{Cd}, \mathrm{H}_{2} \mathrm{O}_{2}$, and MDA and by increasing proline, glycine betaine, SOD, CAT, APX, and GR activities which reduced the oxidative stress. Recently, Farooq et al. (2018) have also reported that exogenous application of MJ to Brassica napus plants alleviated the arsenic-induced oxidative stress and improved overall plant growth and photosynthesis.

\section{Role of JA under cold and heat stress}

Cold stress (chilling and freezing) affect crop productivity because many crops are sensitive and intolerant to low temperature. Acute temperature variation damages the plants (Schwartz et al. 2006). Usually, chilling and freezing stress lead to chlorosis, necrosis, membrane damage, changes in cytoplasm viscosity, and changes in enzyme activities (Ruelland and Zachowski 2010) leading to death of plants. Plants are therefore forced to adaptation to cold stress, and they have evolved many tolerance mechanisms to survive under adverse environmental conditions (Shinozaki et al. 2003). Experiment on Arabis alpina belonging to Brassicaceae family showed variation in JA and other hormones under chilling and freezing conditions (Kolaksazov et al. 2013). All tolerant and non-tolerant plants showed very high level of JA at normal temperature of $22{ }^{\circ} \mathrm{C}$. After chilling stress at
$4{ }^{\circ} \mathrm{C}$, the tolerant plants did not show considerable change in JA relative to 10 -fold reduction in nontolerant plants. Upon exposure to frost (below $0{ }^{\circ} \mathrm{C}$ ), JA content drastically dropped in tolerant plants while the non-tolerant plants had nearly the same level of JA. It indicates that in A. alpina, JA may be the principal jasmonate mediator of the cold stress.

MJ can reduce the negative effect of chilling injury in crop plants. For instance, JA induces accumulation of resveratrol in Vitis vinifera which is a healthy compound for human consumption (Verpoorte et al. 2000). It also induces the formation of many compounds of pharmaceutical interest and antioxidants such as flavonoids and vitamins (Martin et al. 2013). MJ reduces chilling injury in Cucurbita pepo through its regulation of ABA and polyamine levels (Wang and Buta 1994). MJ delays the onset of chilling injury symptoms in C. pepo. MJ-treated plants/fruits showed an increase in ABA level upon exposure to $5{ }^{\circ} \mathrm{C}$ which indicates that it may stimulate ABA synthesis at chilling temperatures. However, the treated and untreated samples had identical increase in putrescine level with a simultaneous decrease in spermidine and spermine contents. MJ and AA have similar effects in reducing chilling injury (Parthier et al. 1992). M) can also enhance the accumulation of ABA in the exocarp tissue of Zucchini squash (Wang and Buta 1994). Perhaps MJ causes an alteration in tissue metabolism followed by an increased synthesis in ABA at chilling temperatures. MJ may act as second messenger of plants to transduct signals and facilitate the expression of defense genes in response to various stresses (Farmer et al. 1992; Gundlach et al. 1992; Reinbothe et al. 1993).

Like cold stress, heat stress also affects plant growth and development. Plants generally develop tolerance against these extreme variations in temperature. Heat stress leads to undesirable changes in plant growth at cellular level impairing cell homeostasis (Bokszczanin et al. 2013). Usually, high temperature forces a plant to synthesize heat shock proteins (HSPs) which prevent denaturation and assist refolding of damaged proteins (Boston et al. 1996). Clarke et al. (2009) have reported that JAs produce thermo tolerance in plants. Exogenous application of low dose of MJ has been shown to maintain the cell viability by controlling electrolyte leakage in heat stressed A. thaliana plants (Clarke et al. 2009). Nevertheless, expression of JA inducible gene PDF1.2 was observed after heat stress exposure. Further, Clarke et al. (2009) have reported the proof of involvement of JA in thermotolerance from mutant analysis of SA and JA signaling mutants (coi1-1, opr3, and jar1-1cpr5-1). In another study, Du et al. (2013) have reported that several genes are involved in JA biosynthesis and signaling were induced by drought and cold treatment, but these genes were suppressed by heat stress in rice plants. 
It was found that the endogenous JA level was increased under drought/cold stresses, but JA level was decreased under heat stress. The role of HSP90 and HSP70 in JACOR responses in HSP90 RNAi lines showing reduction in transcript levels of JA in A. thaliana has also been reported (Zhang et al. 2015). In a recent study, Hou et al. (2018) concluded that lipoxygenase positively contributed to high temperature response and exogenous MJ or SA stimuli. However, exogenous MJ or SA plays a promoting role on its corresponding endogenous phytohormone accumulation in Gracilariopsis lemaneiformis (red alga).

\section{Conclusion}

Jasmonic acid and its methyl ester play a significant role in plant growth and developmental processes under changing environmental as well as other biotic stresses. It has been established that JAs are emerging players in alleviating the deleterious effects under adverse conditions. They induce resistance against many biotic stresses. In plant systems, they regulate gene expression which controls overall plant growth, antioxidant metabolism, osmolyte synthesis, metabolite accumulation, and physiological parameters. Thus, these findings are useful in the development of resilient plants by genetic engineering/manipulation of JA biosynthesis. These hormones are produced only under abnormal conditions such as heat, cold, or salinity to protect the plant and induce resistance against pests and insects. Moreover, under changing environmental condition, JAs' networking and their crosstalk with other plant hormones needs further investigation.

\section{Abbreviations}

ABA: Abscisic acid; APX: Ascorbate peroxidase; CAT: Catalase; GA: Gibberellic acid; GR: Glutathione reductase; $\mathrm{H}_{2} \mathrm{O}_{2}$ : Hydrogen peroxide; IBA: Indole 3butyric acid; JA: Jasmonic acid; JA-lle: $N$-jasmonoyl-L-isoleucine; JAs: Jasmonates; MJ: Methyl jasmonate; NaCl: Sodium chloride; NO: Nitric oxide; POD: Peroxidase; ROS: Reactive oxygen species; SA: Salicylic acid; WIPK: Wound-induced protein kinase

\section{Acknowledgements}

The authors are thankful to the publishers for permission to adopt the figures in this review.

\section{Authors' contributions}

$\mathrm{AH}$ gathered the research data. $\mathrm{AH}$ and $\mathrm{KSS}$ analyzed these data findings and wrote this review paper. Both authors read and approved the final manuscript.

\section{Funding}

Not applicable.

\section{Availability of data and materials}

Not applicable.

Ethics approval and consent to participate

Not applicable.

\section{Consent for publication}

Not applicable.

\section{Competing interests}

The authors declare that they have no competing interests.

\section{Author details}

${ }^{1}$ Department of Chemistry, Aligarh Muslim University, Aligarh, Uttar Pradesh 202002, India. ${ }^{2}$ Wolaita Sodo University, P.O. Box \# 138, Wolaita, Ethiopia.

Received: 19 February 2019 Accepted: 13 September 2019

Published online: 26 October 2019

\section{References}

Ahmad P, Ahanger MA, Alyemeni MN, Wijaya L, Alam P, Ashraf M (2018) Mitigation of sodium chloride toxicity in Solanum lycopersicum L. by supplementation of jasmonic acid and nitric oxide. J Plant Interac 13: $64-72$

Ahmad P, Alyemeni MN, Wijaya L, Alam P, Ahanger MA, Alamri SA (2017) Jasmonic acid alleviates negative impacts of cadmium stress by modifying osmolytes and antioxidants in faba bean (Vicia faba L.). Arch Agro Soil Sci 63: 1889-1899

Ahmad P, Jhon R (2005) Effect of salt stress on growth and biochemical parameters of Pisum sativum L. Arc Agro Soil Sci 51:665-672

Ahmad P, Rasool S, Gul A, Sheikh SA, Akram NA, Ashraf M, Kazi AM, Gucel $S$ (2016) Jasmonates: multifunctional roles in stress tolerance. Front Plant Sci 7:813

Anjum SA, Wang L, Farooq M, Khan I, Xue L (2011) Methyl jasmonate-induced alteration in lipid peroxidation, antioxidative defense system and yield in soybean under drought. J Agron Crop Sci 197:296-301

Antoline MC, Sauchez-Dais M (1992) Photosynthetic nutrient use deficiency, nodule activity and solute accumulation in drought stressed alfalfa plants. Photosynthetica 27:595-604

Asgher M, Khan MIR, Anjum NA, Khan NA (2015) Minimising toxicity of cadmium in plants-role of plant growth regulators. Protoplasma 252:399-413

Ataei N, Moradi H, Akbarpour V (2013) Growth parameters and photosynthetic pigments of marigold under stress induced by jasmonic acid. Not Sci Biol;5: 513-513

Balbi V, Devoto A (2008) Jasmonate signalling network in Arabidopsis thaliana: crucial regulatory nodes and new physiological scenarios. New Phytol 177: 301-318

Balfagón D, Zandalinas SI, Gómez-Cadenas A (2018) High temperatures change the perspective: integrating hormonal responses in citrus plants under co-occurring abiotic stress conditions. Physiol Plant. https://doi. org/10.1111/ppl.12815

Bandurska H, Stroiński A, Kubiś J (2003) The effect of Jasmonic acid on the accumulation of $A B A$, proline and spermidine and its influence on membrane injury under water deficit in two barley genotypes. Acta Physiol Plant 25:279-285

Bannenberg G, Martínez M, Hamberg M, Castresana C (2009) Diversity of the enzymatic activity in the lipoxygenase gene family of Arabidopsis thaliana Lipids 44:85-95.

Bernal-Vicente A, Cantabella D, Hernández JA, Diaz-Vivancos P (2018) The effect of mandelonitrile, a recently described salicylic acid precursor, on peach plant response against abiotic and biotic stresses. Plant Biol (Stuttg) 20:986-994

Bideshki A, Arvin MJ (2013) Interactive effects of methyl jasmonate (MJ) and indole-3 butyric acid (IBA) on growth and bio chemical parameters, bulb and allicin yield of garlic (Allium sativum L.) under drought stress in Iran. Int J Agri Res Rev 3:349-360

Bokszczanin KL, Solanaceae pollen Thermotolerance initial training network (SPOT-ITN) consortium, Fragkostefanakis S (2013) Perspectives on deciphering mechanisms underlying plant heat stress response and thermotolerance. Front Plant Sci 4:315

Boston RS, Viitanen PV, Vierling E (1996) Molecular chaperones and protein folding in plants. Plant Mol Biol 32:191-222

Browse J (2005) Jasmonate: an oxylipin signal with many roles in plants. Vitam Horm 72:431-456

Browse J (2009) Jasmonate passes muster: a receptor and targets for the defence hormone. Annu Rev Plant Biol 60:183-205

Cervilla LM, Blasco B, Rios JJ, Romero L, Ruiz JM (2007) Oxidative stress and antioxidants in tomato (Solanum lycopersicum) plants subjected to boron toxicity. Ann Bot 100:747-756 
Charparzadeh N, Lucia M, Negad R, Izzo R, Izzo F (2004) Antioxidative responses of Calendula officinalis under salinity conditions. Plant Physio Biochem 42:695-701

Chen J, Yan Z, Li X (2014) Effect of methyl jasmonate on cadmium uptake and antioxidative capacity in Kandelia obovata seedlings under cadmium stress. Ecotoxicol Environ Saf 104:349-356

Cherki G, Ahmed F, Khalid F (2002) Effects of salt stress on growth, inorganic ions and proline accumulation in relation to osmotic adjustment in five sugar beet cultivars. Environ Exp Bot 47:39-50

Clarke SM, Cristescu SM, Miersch O, Harren FJ, Wasternack C, Mur LA (2009) Jasmonates act with salicylic acid to confer basal thermotolerance in Arabidopsis thaliana. New Phytol 182:175-187

Cohen S, Flescher E (2009) Methyl jasmonate: a plant stress hormone as an anticancer drug. Phytochemistry 70:1600-1609

Colebrook EH, Thomas SG, Phillips AL, Hedden P (2014) The role of gibberellin signalling in plant responses to abiotic stress. J Exp Biol 217:67-75

Dhankar R, Solanki R (2011) Effect of copper and zinc toxicity on physiological and biochemical parameters in Vigna mungo (L.). Hepper. Int J Pharm Bio Sci 2:553-565

Du H, Liu H, Xiong L (2013) Endogenous auxin and jasmonic acid levels are differentially modulated by abiotic stresses in rice. Front Plant Sci 4:397

Durrant WE, Dong X (2004) Systemic acquired resistance. Annu Rev Phytopatho 42:185-209

Ellinger D, Stingl N, Kubigsteltig II, Bals T, Juenger M, Pollmann S, Berger S, Schuenemann D, Mueller MJ (2010) DONGLE and DEFECTIVE IN ANTHER DEHISCENCE1 lipases are not essential for wound- and pathogen-induced jasmonate biosynthesis: redundant lipases contribute to jasmonate formation. Plant Physiol 153:114-127

Embiale A, Hussein A, Husen A, Sahile S, Mohammed K (2016) Differential sensitivity of Pisum sativum L. cultivars to water-deficit stress: changes in growth, water status, chlorophyll fluorescence and gas exchange attributes. Agron 15:45-57

Essa TA (2002) Effect of salinity stress on growth and nutrient composition of three soybean (Glycine max L. Merrill) culti vars. J Agro Crop Sci 188:86-93

Farmer EE, Johnson RR, Ryan CA (1992) Regulation of expression of proteinase inhibitor genes by methyl jasmonate and jasmonic acid. Plant Physiol 98: 995-1002

Faroog MA, Zhang K, Islam F, Wang J, Athar HUR, Nawaz A, Ullah Zafar Z, Xu J, Zhou W (2018) Physiological and iTRAQ-based quantitative proteomics analysis of methyl jasmonate-induced tolerance in Brassica napus under arsenic stress. Proteomics 8:e1700290

Faroogi AA, Butt G, Razzaq Z (2012) Algae extracts and methyl jasmonate anticancer activities in prostate cancer: choreographers of 'the dance macabre'. Cancer Cell Intern 12:50

Gallego SM, Pena LB, Bracia RA, Azpilicueta CE, Lannone MF, Rosales EP, Zawoznik MS, Groppa MD, Benavides MP (2012) Unravelling cadmium toxicity and tolerance in plants: insight into regulatory mechanisms. Environ Exp Bot 83:33-46

Gao FK, Ren CG, Dai CC (2012) Signaling effects of nitric oxide, salicylic acid, and reactive oxygen species on isoeuphpekinensin accumulation in Euphorbia pekinensis suspension cells induced by an endophytic fungal elicitor. J Plant Growth Regul 31:490-497

Getnet Z, Husen A, Fetene M, Yemata G (2015) Growth, water status, physiological, biochemical and yield response of stay green sorghum \{Sorghum bicolor (L.) Moench\} varieties - a field trial under drought-prone area in Amhara regional state, Ethiopia. J Agron 14:188-202

Gfeller A, Liechti R, Farmer EE (2010) Arabidopsis jasmonate signaling pathway. Sci Signal 3:cm4

Ghasemnezhad M, Javaherdashti M (2008) Effect of methyl jasmonate treatment on antioxidant capacity: internal quality and postharvest life of raspberry fruit. Caspian J Env Sci 6:73-78

Gill SS, Tuteja N (2010) Reactive oxygen species and antioxidant machinery in abiotic stress tolerance in crop plants. Plant Physiol Bioch 48:909-930

Gille G, Singler K (1995) Oxidative stress in living cells. Folia Microbiol 2:131-152

Glazebrook J (2005) Contrasting mechanisms of defence against biotrophic and necrotrophic pathogens. Annu Rev Phytopathol 43:205-227

Gundlach H, Mtller M, Kutchan TM, Zenk MH (1992) Jasmonic acid is a signal transducer in elicitor-induced plant cell culture. Proc Natn Acad Sci USA 89:2389-2393

Gunes A, Inal A, Bagci EG, Coban S, Sahin O (2007) Silicon increases B tolerance and reduces oxidative damage of wheat grown in soil with excess $\mathrm{B}$. Biol Plant 51:571-574
Hamberg M, Gardner HW (1992) Oxylipin pathway to jasmonates: biochemistry and biological significance. Biochim Biophys Acta 1165:1-18

Hanaka A, Lechowski L, Mroczek-Zdyrska M, Strubińska J (2018) Oxidative enzymes activity during abiotic and biotic stresses in Zea mays leaves and roots exposed to $\mathrm{cu}$, methyl jasmonate and Trigonotylus caelestialium. Physiol Mole Biol Plant 24:1-5

Harrison MA (2012) Cross-talk between phytohormone signaling pathways under both optimal and stressful environmental conditions. In: Khan NA, Nazar R, lqbal N, Anjum NA (eds) Phytohormones and abiotic stress tolerance in plants. Springer-Verlag, Berlin Heidelberg, pp 49-76

Horbowicz M, Mioduszewska H, Koczkodaj D, Saniewski M (2009) The effect of cis-jasmone, Jasmonic acid and methyl jasmonate on accumulation of anthocyanins and proanthocynidins in seedlings of common buckwheat (Fagopyrum esculentum Moench). Acta Soc Bot Pol 78:271-277

Hou S, Lin L, LV Y, Xu N, Sun X (2018) Responses of lipoxygenase, jasmonic acid, and salicylic acid to temperature and exogenous phytohormone treatments in Gracilariopsis lemaneiformis (Rhodophyta). J Appl Phycol 30:3387-3394

Hou W, Chen X, Guanling S, Wang Q, Chang CC (2007) Effects of copper and cadmium on heavy metal polluted water body restoration by duck weed (Lemna minor). Plant Physiol Biochem 45:62-69

Hu XL, Jiang MY, Zhang JH, Zhang AY, Lin F, Tan MP (2007) Calcium-calmodulin is required for abscisic acid-induced antioxidant defense and functions both upstream and downstream of $\mathrm{H}_{2} \mathrm{O}_{2}$ production in leaves of maize (Zea mays) plants. New Phytol 173:27-38

Huang H, Liu B, Liu L, Song S (2017) Jasmonate action in plant growth and development. J Exp Bot 68:1349-1359.

Huang D, Wu W, Abrams SR, Adrian J, Cutler AJ (2008) The relationship of drought-related gene expression in Arabidopsis thaliana to hormonal and environmental factors. J Exp Bot 59:2991-3007

Hurkman WJ, Tanaka CK (1996) Effect of salt stress on germin gene expression in barley roots. Plant Physiol 110:971-977

Husen A, labal M, Aref IM (2014) Growth, water status and leaf characteristics of Brassica carinata under drought and rehydration conditions. Braz J Bot 37:217-227

Husen A, Iqbal M, Aref IM (2016) IAA-induced alteration in growth and photosynthesis of pea (Pisum sativum L.) plants grown under salt stress. J Environ Biol 37:421-429

Husen A, Iqbal M, Aref IM (2017) Plant growth and foliar characteristics of faba bean (Vicia faba L.) as affected by indole-acetic acid under water-sufficient and water-deficient conditions. J Environ Biol 38:179-186

Husen A, lqbal M, Khanum N, Aref IM, Sohrab SS, Meshresa G (2019) Modulation of salt-stress tolerance of Niger (Guizotia abyssinica), an oilseed plant, by application of salicylic acid. J Environ Biol 40:94-104

Husen A, labal M, Sohrab SS, Ansari MKA (2018) Salicylic acid alleviates salinitycaused damage to foliar functions, plant growth and antioxidant system in Ethiopian mustard (Brassica carinata a. Br.). Agri food Secur 7:44

Inal A, Pilbeam DJ, Gunes A (2009) Silicon increases tolerance to B toxicity and reduces oxidative damage in barley. J Plant Nutr 32:112-128

labal M, Ahmad A, Ansari MKA, Qureshi MI, Aref IM, Khan PR, Hegazy SS, El-Atta $H$, Husen A, Hakeem KR (2015) Improving the phytoextraction capacity of plants to scavenge metal (loid)-contaminated sites. Environ Rev 23:44-65

Ishiguro S, Kawai-Oda A, Ueda J, Nishida I, Okada K (2001) The defective in anther dehiscience gene encodes a novel phospholipase A1 catalyzing the initial step of Jasmonic acid biosynthesis, which synchronizes pollen maturation, anther dehiscence, and flower opening in Arabidopsis. Plant Cell 13:2191-2209

Ismail A, Seo M, Takebayashi Y, Kamiya Y, Eiche E, Nick P (2014) Salt adaptation requires efficient fine-tuning of jasmonate signaling. Protoplasma 251:881-898

James DG (2005) Further field evaluation of synthetic herbivore-induced plan volatiles as attractants for beneficial insects. J Chem Ecol 31:481-495

Jiang MY, Zhang HH (2002) Water stress-induced abscisic acid accumulation triggers the increased generation of reactive oxygen species and up-regulates the activities of antioxidant enzymes in maize leaves. J Exp Bot 53:2401-2410

Jung HW, Tschaplinski TJ, Wang L, Glazebrook J, Greenberg JT (2009) Priming in systemic plant immunity. Science 324:89-91

Kang DJ, Seo YJ, Lee JD, Ishii R, Kim KU, Shin DH, Park SK, Jang SW, Lee IJ (2005) Jasmonic acid differentially affects growth, ion uptake and abscisic acid concentration in salt-tolerant and salt-sensitive rice cultivars. J Agro Crop Sci. 191:273-282

Katsir L, Chung HS, Koo AJ, Howe GA (2008) Jasmonate signaling: a conserved mechanism of hormone sensing. Cur Opin Plant Biol 11:428-435 
Kaya CH, Kirnak H, Higgs K (2001) Enhancement of growth and normal growth parameters by foliar application of potassium and phosphorus in tomato cultivars grown at high ( $\mathrm{NaCl}$ ) salinity. J Plant Nut 24:357-367

Kazan K (2013) Auxin and the integration of environmental signals into plant root development. Ann Bot 112:1655-1665

Kazan K (2015) Diverse roles of jasmonates and ethylene in abiotic stress tolerance. Trends Plant Sci 20:219-229

Khan W, Prithiviraj B, Donald SL (2003) Photosynthetic responses of corn and soybean to foliar application of salicylates. J Plant Physiol 160:485-492

Kim EH, Kim YS, Park SH, Koo YJ, Choi YD, Chung YY, Lee IJ, Kim JK (2009b) Methyl jasmonates reduces grain yield by mediating stress signals to alter spikelet development in rice. Plant Physiol 149:1751-1760

Kim SK, Sohn EY, Joo GJ, Lee IJ (2009a) Influence of jasmonic acid on endogenous gibberellin and abscisic acid in salt-stressed chard plant. J Environ Biol 30:333-338

Kolaksazov M, Laporte F, Ananieva K, Dobrev P, Herzog M, Ananiev ED (2013) Effect of chilling and freezing stresses on jasmonate content in Arabis alpina. Bulgarian J Agri Sci 19:15-17

Kombrink E (2012) Chemical and genetic exploration of jasmonate biosynthesis and signaling paths. Planta 236:1351-1366

Ku K, Choi J-H, Kushad M, Jeffery E, Juvik J (2013) Pre-harvest methyl jasmonate treatment enhances cauliflower chemoprotective attributes without a loss in postharvest quality. Plant Foods Hum Nutr 68:113-117

Kunkel BN, Brooks DM (2002) Cross talk between signaling pathways in pathogen defense. Curr Opin Plant Biol 5:325-331

Li C, Fang B, Yang C, Shi D, Wang D (2009) Effects of various salt-alkaline mixed stresses on the state of mineral elements in nutrient solutions and the growth of alkali resistant halophyte Chlorisvirgata. J Plant Nutr 32:1137-1147

Lin T, Sharma P, Gonzalez DH, Viola IL, Hannapel DJ (2013) The impact of the long-distance transport of a BEL1-like messenger RNA on development. Plant Physiol 161:760-772

Liu S, Zhang P, Li C, Xia G (2019) The moss jasmonate ZIM-domain protein PnJAZ1 confers salinity tolerance via crosstalk with the abscisic acid signalling pathway. Plant Sci 280:1-11

Liu X, Shi WL, Zhang SQ, Lou CH (2005) Nitric oxide participates in the signal transduction of stomatal closure induced by jasmonic acid in Vicia faba $\mathrm{L}$. Chin Sci Bull 50:453-458

Maksymiec W, Wianowska D, Dawidowicz AL, Radkiewicz S, Mardarowicz M, Krupa Z (2005) The level of jasmonic acid in Arabidopsis thaliana and Phaseolus coccineus plants under heavy metal stress. J Plant Physiol 162:1338-1346

Martin C, Zhang Y, Tonelli C, Petroni K (2013) Plants, diet, and health. Annu Rev Plant Biol 64:19-46

Mir MA, John R, Alyemeni MN, Alam P, Ahmad P (2018) Jasmonic acid ameliorates alkaline stress by improving growth performance, ascorbate glutathione cycle and glyoxylase system in maize seedlings. Sci Rep 8:2831

Moons A, Prinsen E, Bauw G, Montagu MV (1997) Antagonistic effects of abscisic acid and jasmonates on salt stress-inducible transcripts in rice roots. Plant Cell 9:2243-2259

Moya JL, Gomez-Cadenas A, Primo-Millo E, Talon M (2003) Chloride absorption in salt-sensitive Carrizo citrange and salt-tolerant Cleopatra mandarin citrus rootstocks is linked to water use. J Exp Bot 54:825-833

Mucciarelli M, Camusso W, Maffei M, Panicco P, Bicchi C (2007) Volatile terpenoids of endophyte-free and infected peppermint (Mentha piperita L.): chemical partitioning of a symbiosis. Microb Ecol 54:685-696

Munemasa S, Oda K, Watanabe-Sugimoto M, Nakamura Y, Shimoishi Y, Murata Y (2007) The coronatine-insensitive 1 mutation reveals the hormonal signaling interaction between abscisic acid and methyl jasmonate in Arabidopsis guard cells. Specific impairment of ion channel activation and second messenger production. Plant Physiol 143:1398-1407

Munns R, Termaat A (1986) Whole-plant responses to salinity. Aust J Plant Physiol 13:143-160

Nable RO, Bañuelos GS, Paull JG (1997) Boron toxicity. Plant Soil 193:181-198

Nafie E, Hathout T, Mokadem ASA (2011) Jasmonic acid elicits oxidative defense and detoxification systems in Cucumis melo L. cells. Braz J Plant Physiol 23:161-174

Nandwal AS, Godara M, Sheokand S, Kamboj DV, Kundu BS, Kuhad MS, Kumar B, Sharma SK (2000) Salinity induced changes in plant water status, nodule function and ionic distribution in phenotypically differing genotypes of Vigna radiata L. J Plant Physiol 156:350-359

Nojiri H, Sugimori M, Yamane H, Nishimura Y, Yamada A, Shibuya N, Kodama O, Murofushi N, Omori T (1996) Involvement of jasmonic acid in elicitor- induced phytoalexin production in suspension-cultured rice cells. Plant Physiol 110:387-392

Noriega G, Cruz DS, Batlle A, Tomaro M, Balestrasse K (2011) Heme oxygenase is involved in the protection exerted by Jasmonic acid against cadmium stress in soybean roots. J Agron Crop Sci 197:296-301

Pandey P, Irulappan V, Bagavathiannan MV, Senthil-Kumar M (2017) Impact of combined abiotic and biotic stresses on plant growth and avenues for crop improvement by exploiting physio-morphological traits. Front Plant Sci 8:537

Park JH, Halitschke R, Kim HB, Baldwin IT, Feldmann KA, Feyereisen R (2002) A knock-out mutation in allene oxide synthase results in male sterility and defective wound signal transduction in Arabidopsis due to a block in jasmonic acid biosynthesis. Plant J 31:1-12

Parthier B, Brtickner C, Dathe W, Hause B, Herrmann G, Knofel HD, Kramell HM, Kramell R, Lehmann J, Miersch O, Reinbothe S, Sembdner G, Wasternack C, Zur Nieden U. Jasmonates: metabolism, biological activities, and modes of action in senescence and stress responses. In: Progress in plant growth regulation. Karssen CM, van Loon LC, Vreugdenhil D (eds.) Kluwer Academic Publishers. Netherlands 1992; pp. 276-285

Paull JG, Nable RO, Lake AWH, Materne MA, Rathjen AJ (1992) Response of annual medics (Medicago spp.) and fi eld peas (Pisum sativum) to high concentrations of boron: genetic variation and mechanism of tolerance. Aust J Agric Res 43:203-213

Pauwels L, Inze D, Goossens A (2009) Jasmonate-inducible gene: what does it mean? Trends Plant Sci 14:87-91

Per TS, Khan MIR, Anjum NA, Masood A, Hussain SJ, Khan NA (2018) Jasmonates in plants under abiotic stresses: crosstalk with other phytohormones matters. Environ Exp Bot 145:104-120

Pieterse CMJ, van der Does D, Zamioudis C, Leon-Reyes A, van Wees SCM (2012) Hormonal modulation of plant immunity. Ann Rev Cell Develop Biol 28:489-521

Podlešáková K, Ugena L, Spíchal L, Doležal K, De Diego N (2019) Phytohormones and polyamines regulate plant stress responses by altering GABA pathway. New Biotechnol 48:53-65

Poonam S, Kaur H, Geetika S (2013) Effect of jasmonic acid on photosynthetic pigments and stress markers in Cajanus cajan (L.) mill sp. seedlings under copper stress. Am J Plant Sci 4:817-823

Popova LP, Stoinova ZG, Maslenkova LT (1995) Involvement of abscisic acid in photosynthetic process in Hordeum vulgare L. during salinity stress. J Plant Growth Regul 14:211-218

Qiun ZB, Guo JL, Zhu AJ, Zhang L, Zhang MM (2014) Exogenous jasmonic acid can enhance tolerance of wheat seedlings to salt stress. Ecotoxicol Environ Saf 104:202-208

Reinbothe C, Springer A, Samol I, Reinbothe S (2009) Plant oxylipins: role of jasmonic acid duringprogrammed cell death, defence and leaf senescence. FEBS J 276:4666-4681

Reinbothe S, Reinbothe C, Parthier B (1993) Methyl jasmonate represses translation initiation of a specific set of mRNAs in barley. Plant J 4:459-467

Ren CG, Dai CC (2012) Jasmonic acid is involved in the signaling pathway for fungal endophyte-induced volatile oil accumulation of Atractylodes lancea plantlets. BMC Plant Biol 12:128

Rodriguez RJ, White JJF, Arnold AE, Redman RS (2009) Fungal endophytes: diversity and functional roles. New Phytol 182:314-330

Rohwer C, Erwin J (2008) Horticultural applications of jasmonates: a review. J Horti Sci Biotechnol 83:283-304

Ruelland E, Zachowski A (2010) How plants sense temperature. Environ Exp Bot 69:225-232

Santino A, Taurino M, De Domenico S, Bonsegna S, Poltronieri P, Pastor V, Flors V (2013) Jasmonate signaling in plant development and defense response to multiple (a) biotic stresses. Plant Cell Rep 32:1085-1098

Sasaki-Sekimoto Y, Taki N, Obayashi T (2005) Coordinated activation of metabolic pathways for antioxidants and defence compounds by jasmonates and their roles in stress tolerance in Arabidopsis. Plant J 44:653-668

Schmelz EA, Grebenok RJ, Ohnmeiss TE, Bowers WS (2002) Interactions between Spinacia oleracea and Bradysia impatiens: a role for phytoecdysteriods. Arch Insect Biochem Physiol 51:204-221

Schwartz M, Ahas R, Aasa A (2006) Onset of spring starting earlier across the northern hemisphere. Glob Chang Biol 12:343-351

Seo HS, Song JT, Cheong JJ, Lee YH, Lee YH, Hwang I, Lee JS, Yang DC (2001) Jasmonic acid carboxylmethyltransferase: a key enzyme for jasmonate regulated plant responses. Proc Natl Acad Sci U S A 98:4788-4793

Seo JS, Joo J, Kim MJ, Kim YK, Nahm BH, Song SI, Cheong JJ, Lee JS, Kim JK, Choi YD (2011) OsbHLH148, a basic helix-loop-helix protein, interacts with OsJAZ 
proteins in a jasmonate signaling pathway leading to drought tolerance in rice. Plant J 65:907-921

Shan C, Liang Z (2010) Jasmonic acid regulates ascorbate and glutathione metabolism in Agropyron cristatum leaves under water stress. Plant Sci 178:130-139

Sheteawi SA (2007) Improving growth and yield of salt-stressed soybean by exogenous application of jasmonic acid and ascobin. Int J Agri Biol 9:473-478

Shinozaki K, Yamaguchi-Shinozaki K, Seki M (2003) Regulatory network of gene expression in the drought and cold stress responses. Curr Opinion Plant Biol 6:410-417

Siddiqi KS, Husen A (2017) Plant response to strigolactones: current developments and emerging trends. Appl Soil Ecol 120:247-253

Singh I, Shah K (2014) Exogenous application of methyl jasmonate lowers the effect of cadmium-induced oxidative injury in rice seedlings. Phytochemistry 108:57-66

Song S, Qi T, Huang H, Ren Q, Wu D, Chang C, Peng W, Liu Y, Peng J, Xie D (2011) The Jasmonate-ZIM domain proteins interact with the R2R3-MYB transcription factors MYB21 and MYB24 to affect Jasmonate-regulated stamen development in Arabidopsis. Plant Cell 23:1000-1013

Soriano IR, Asenstorfer RE, Schmidt O, Riley IT (2004) Inducible flavone in oats (Avena sativa) is a novel defense against plant-parasitic nematodes. Phytopathology 94:1207-1214

Thaler JS, Stout MJ, Karban R, Duffey SS (2001) Jasmonate-mediated induced plant resistance affects a community of herbivores. Ecol Entomol 26:312-324

Van LC, Van EA (1999) The families of pathogenesis related proteins, their activities, and comparative analysis of PR-1 type proteins. Physiol Mole Plant Pathol 55:85-97

van Poppel G, Verhoeven D, Verhagen H, Goldbohm R (1999) Brassica vegetables and cancer prevention. Epidemiology and mechanisms. Adv Exp Med Biol 472:159-168

Verpoorte R, van der Heijden R, Memelink J (2000) Engineering the plant cell factory for secondary metabolite production. Transgenic Res 9:323-343

von Malek B, van der Graaff E, Schneitz K, Keller B (2002) The Arabidopsis malesterile mutant dde2-2 is defective in the ALLENE OXIDE SYNTHASE gene encoding one of the key enzymes of the jasmonic acid biosynthesis pathway. Planta 216:187-192

Walia H, Wilson C, Condamine P, Liu X, Ismail AM, Close TJ (2007) Large-scale expression profiling and physiological characterization of jasmonic acidmediated adaptation of barley to salinity stress. Plant Cell Environ 30:410-421

Walia H, Wilson C, Wahid A, Condamine P, Cui X, Close TJ (2006) Expression analysis of barley (Hordeum vulgare L.) during salinity stress. Funct Integr Genom 6:143-156

Wang A, Zhang F, Huang L, Yin X, Li H, Wang Q, Zeng Z, Xie T (2010) New progress in biocatalysis and biotransformation of flavonoids. J Med Plants Res 4:847-856

Wang CY, Buta JG (1994) Methyl jasmonate reduces chilling injury in Cucurbita pepo through its regulation of abscisic acid and polyamine levels. Environ Exp Bot 34:427-432

Wang H, Wu Z, Chen Y, Yang C, Shi D (2011b) Effects of salt and alkali stresses on growth and ion balance in rice (Oryza sativa L.). Plant Soil Environ 57:286294

Wang Y, Dai CC, Zhao YW, Peng Y (2011a) Fungal endophyte-induced volatile oil accumulation in Atractylodes lancea plantlets is mediated by nitric oxide, salicylic acid and hydrogen peroxide. Process Biochem 46:730-735

Wang Y, Mopper S, Hasenstein KH (2001) Effects of salinity on endogenous ABA, IAA, JA, and SA in Iris hexagona. J Chem Ecol 27:327-342

Wasternack C (2007) Jasmonates: an update on biosynthesis, signal transduction and action in plant stress response, growth and development. Ann Bot 100:681-697

Wasternack C, Hause B (2013) Jasmonates: biosynthesis, perception, signal transduction and action in plant stress response, growth and development. An update to the 2007 review in annals of botany. Ann Bot 111:1021-1058

Wasternack C, Song S (2017) Jasmonates: biosynthesis, metabolism: and signaling by proteins activating and repressing transcription. J Exp Bot 68:1303-1321

Wu J, Hettenhausen C, Meldau S, Baldwin IT (2007) Herbivory rapidly activates MAPK signaling in attacked and unattacked leaf regions but not between leaves of Nicotiana attenuata. Plant Cell 19:1096-1122

Xin ZY, Zhou X, Pilet PE (1997) Level changes of jasmonic, abscisic and indole-3yl acetic acids in maize under desiccation stress. J Plant Physiol 151:120-124

Xue R, Zhang B (2007) Increased endogenous methyl jasmonate altered leaf and root development in transgenic soybean plants. J Genet Genom 34:339-346
Yan Z, Chen J, Li X (2013) Methyl jasmonate as modulator of cd toxicity in Capsicum frutescens var: fasciculatum seedlings. Ecotoxicol Environ Saf 98:203-209

Yan Z, Li X, Chen J, Tam NF (2015) Combined toxicity of cadmium and copper in Avicennia marina seedlings and the regulation of exogenous jasmonic acid. Ecotoxicol Environ Saf 113:124-132

Yang DH, Hettenhausen C, Baldwin IT, Wu J (2012) Silencing Nicotiana attenuata calcium-dependent protein kinases, CDPK4 and CDPK5, strongly up-regulates wound- and herbivory-induced jasmonic acid accumulations. Plant Physiol 159:1591-1607

Yang W, Devaiah SP, Pan X, Isaac G, Welti R, Wang X (2007) AtPLAl is an acyl hydrolase involved in basal jasmonic acid production and Arabidopsis resistance to Botrytis cinerea. J Chem Biol 282:18116-18128

Yeo AR, Flowers SA, Rao G, Welfare K, Senanayake N, Flowers TJ (1999) Silicon reduces sodium uptake in rice (Oryza sativa L.) in saline conditions and this is accounted for by a reduction in the transpirational bypass flow. Plant Cell Environ 22:559-565

Yeo AR, Flowers TJ (1986) Salinity resistance in rice (Oryza sativa L.) and a pyramiding approach to breeding varieties for saline soils. Aust J Plant Physiol 13:161-173

Yoon JY, Hamayun M, Lee SK, Lee IJ (2009) Methyl jasmonate alleviated salinity stress in soybean. J Crop Sci Biotech 12:63-68

Yoshida Y, Sano R, Wada T, Takabayashi J, Okada K (2009) Jasmonic acid control of GLABRA3 links inducible defense and trichome patterning in Arabidopsis. Development 136:1039-1048

Yuan F, Liang X, Li Y, Yin S, Wang B (2018) Methyl jasmonate improves tolerance to high salt stress in the recretohalophyte Limonium bicolor. Fun Plant Biol 46:82-92

Yuan Y, Li C, Hu Z (2001) Signal transduction pathway for oxidative burst and taxol production in suspension cultures of Taxus chinensis vat mairei induced by oligosaccharide from Fusarium oxysprum. Enzym Microb Technol 29:372-379

Yurchenko O, Kimberlin A, Mehling M, Koo AJ, Chapman KD, Mullen RT, Dyer JM (2018) Response of high leaf-oil Arabidopsis thaliana plant lines to biotic or abiotic stress. Plant Signal Behav 13:e1464361

Zeevaart JAD, Creelman RA (1988) Metabolism and physiology of abscisic acid. Ann Rev Plant Physiol Plant Mol Biol 39:439-475

Zhang XC, Millet YA, Cheng Z, Bush J, Ausubel FM (2015) Jasmonate signalling in Arabidopsis involves SGT1b-HSP70-HSP90 chaperone complexes. Nat Plants 1:15049

Zhang ZP, Baldwin IT (1997) Transport of [2-C- $\left.{ }^{14}\right]$ jasmonic acid from leaves to roots mimics wound-induced changes in endogenous jasmonic acid pools in Nicotiana sylvestris. Planta 203: 436-441

Zoeller M, Stingl N, Krischke M, Fekete A, Waller F, Berger S, Mueller MJ (2012) Lipid profiling of the Arabidopsis hypersensitive response reveals specific lipid peroxidation and fragmentation processes: biogenesis of pimelic and azelaic acid. Plant Physiol 160:365-378

\section{Publisher's Note}

Springer Nature remains neutral with regard to jurisdictional claims in published maps and institutional affiliations.

\section{Submit your manuscript to a SpringerOpen ${ }^{\circ}$ journal and benefit from:}

- Convenient online submission

- Rigorous peer review

- Open access: articles freely available online

- High visibility within the field

- Retaining the copyright to your article

Submit your next manuscript at $>$ springeropen.com 